\title{
Novel unorthodox strategies to reduce the case fatality rate of COVID-19 in high risk groups
}

\author{
Hlavaty $\mathrm{T}^{1,2}$, Krajcovicova $\mathrm{A}^{2}$ \\ Department of Internal Medicine V., Comenius University Faculty of Medicine, University Hospital \\ Bratislava, Slovakia. tibor.hlavaty2@gmail.com
}

\begin{abstract}
Dear editors: We propose novel strategies to combat the COVID-19 outbreak, that are aimed at high-risk groups and might reduce the progression to severe forms of COVID and thus decrease the very high case fatality rate.

Following the first reports of the outbreak of several cases of acute respiratory distress syndrome in the Chinese city of Wuhan at the end of December 2019, a novel beta coronavirus, named severe acute respiratory syndrome coronavirus 2 (SARS-CoV-2 or 2019-nCoV) as the main causative agent was identified while the disease associated with was named by WHO as COVID-19 $(1,2)$.

The outbreak has rapidly spread globally with more than 150.000 cases detected in over 100 countries as of March 13, 2020. The overall case-fatality rate (CFR) of COVID-19 in China was $2.3 \%$, but globally it seems to be higher in the range of 3-5\% (3). At present, no specific antivirals or approved vaccines are available to combat COVID-19. Many patients however receive off-label antivirals such as lopinavir/ritonavir, ribavirin and/or chloroquine and /or interferons. Several new antivirals such as remdesivir are studied in ongoing clinical trials.

Given the alarming global situation and rapidly evolving large scale pandemics, there is an urgent need for effective strategies to prevent the spread of the disease and decrease its high CFR. The gravity of the situation requires to consider even novel unorthodox strategies to control the outbreak and high lethality of COVID-19. (Tab. 2, Ref. 21). Text in PDF www.elis.sk KEY WORDS: COVID-19, coronavirus, distress syndrome, lopinavir/ritonavir, ribavirin, chloroquine, interferons.
\end{abstract}

\section{Risk factors of severe pneumonia in COVID-19}

According to a large epidemiological study of COVID-19 from Chinese Center for Disease Control and Prevention, the overall case-fatality rate (CFR) was $2.3 \%$ (1023/44 672 confirmed cases) (3). The most important risk factors for severe morbidity and mortality are older age and comorbidities.

In patients with no pre-existing conditions the CFR was however only $0.9 \%$. Those aged 70 to 79 years had an $8.0 \%$ CFR and cases in those aged 80 years and older had a $14.8 \%$ CFR. CFR was elevated among those with pre-existing comorbid conditions $10.5 \%$ for cardiovascular disease, $7.3 \%$ for diabetes, $6.3 \%$ for chronic respiratory disease, $6.0 \%$ for hypertension, and $5.6 \%$ for cancer. Among the 44672 cases, a total of 1716 were health care professionals $(3.8 \%)$. In this group $5(0.3 \%)$ deaths were observed

A recent retrospective analysis of 191 severe inpatients with COVID-19 from Wuhan revealed that comorbidities were present in nearly half of the patients, with hypertension being the

${ }^{1}$ Department of Internal Medicine V, Comenius University Faculty of Medicine, University Hospital Bratislava, Bratislava, Slovakia and ${ }^{2}$ Gastroenterology Center Ruzinov, Bratislava, Slovakia

Address for correspondence: Prof. T.Hlavatý, MD, PhD, Departmnt of Internal Medicine V, Comenius University Faculty of Medicine, University hospital Bratislava, Ruzinovska 6, SK-826 06 Bratislava, Slovakia. most common, followed by diabetes and coronary heart disease (4). The median age of the analysed 191 patients was 56.0 years (IQR 46.0-67.0) and most patients were male. Comorbidities were a significant predictor of mortality, including hypertension with OR 3.05 (1.57-5.92) (48\% of non-survivors vs $23 \%$ in survivors, $\mathrm{p}=0.0008)$, diabetes with OR $2.85(1.35-6.05)(31 \%$ vs $14 \%$, $\mathrm{p}=0.005)$, coronary heart disease with OR 21.40 (4.64-98.76) ( $24 \%$ vs $1 \%, \mathrm{p}<0.0001$, chronic kidney disease (CKD), (4\% vs $0 \%, \mathrm{p}=0.02)$.

From another perspective the overall CFR in hospitalized patients with hypertension was 26/58 (45\%) in those with diabetes $17 / 36(47 \%)$, coronary heart disease $13 / 15$ (87\%) and both hospitalized CKD patients died. On the other hand, CFR in patients with severe COVID-19 and no comorbidities was 18/100 (18\%).

In a study conducted by Guan et al, which included 1099 patients with confirmed COVID-19, 173 had severe disease with comorbidities of hypertension $(23.7 \%)$, diabetes mellitus $(16.2 \%)$, coronary heart diseases $(5.8 \%)$, and cerebrovascular disease $(2.3 \%)(5)$.

It has been confirmed that $2019-\mathrm{nCoV}$ uses the same cell entry receptor-angiotensin converting enzyme II (ACE2) - as SARSCoV (2) (6). Recently it has been hypothesised that patients with cardiac diseases, hypertension, or diabetes, who are treated with ACE2-upregulating drugs such as ACEi, ARB or spironolactone are at higher risk of severe COVID-19 infection (7). 


\section{Implications for prevention and treatment of severe COV- ID-19 in high-risk groups}

The above presented hypothesis leads to some very important implications, that should be considered, given the severity of the rapidly evolving COVID-19 pandemics. There are large groups of population that are at high-risk of developing severe forms of COVID-19. These include seniors ( $>65$ years) and/or patients with commorbidities such as hypertension, diabetes and coronary heart disease,

\section{Chemoprophylaxis in high risk groups}

There are two widely available medications that were shown to inhibit the SARS-CoV proteases, hydroxychloroquine (HCQ, Plaquenil) or chloroquine (CQ, various generic brands) and lopinavir/ritonavir (LPV/r, Kaletra or Alluvia, AbbVie). Others such as remdesivir are late stages of clinical development.

\section{Chloroquine/Hydroxychloroquine}

Chloroquine (CQ) or hydroxychloroquine (HCQ, has been used worldwide for more than 70 years for the treatment and prophylaxis of malaria. It is widely available, cheap and has an established clinical safety profile. Other uses include treatment of rheumatoid arthritis, lupus, and porphyria cutanea tarda. Besides its antiviral activity, chloroquine has an immune-modulating activity, which may synergistically enhance its antiviral effect in vivo. Chloroquine is widely distributed in the whole body, including lung, after oral administration. Chloroquine is extensively distributed with an enormous total apparent volume of distribution (Vd) more than $100 \mathrm{~L} / \mathrm{kg}$, and a terminal elimination half-life of 1 to 2 months (8). As a consequence, distribution rather than elimination processes determine the blood concentration profile of chloroquine. Caution has to be exercised for the development of QT prolongation on ECG, development of hypoglycemia, anxiety and retinopathy.

Very recently CQ has been shown to be effective in reducing viral replication of coronavirus SARS-CoV-2. Effective concentration (EC) 90 of $6.90 \mu \mathrm{M}$ can be easily achieved with standard dosing, due to its favourable penetration in tissues, including the lung (9). Vincent et al observed that the inhibitory effects of chloroquine on SARS-CoV infectivity and cell spread occurred in the presence of $1-10 \mu \mathrm{M}$ chloroquine, which are plasma concentrations achievable during the prophylaxis and treatment of malaria (varying from $1.6-12.5 \mu \mathrm{M})$ and hence are well tolerated by patients $(10$, 11). Concentrations of $10 \mu \mathrm{M}$ completely abolished SARS-CoV infection. Pre-treatment with 1 and $10 \mu \mathrm{M}$ chloroquine reduced infectivity by $53 \%$, and $100 \%$, respectively. When chloroquine was added after the initiation of infection, there was a dramatic dose-dependent decrease in the number of virus antigen-positive cells. As little as $0.1-1 \mu \mathrm{M}$ chloroquine reduced the infection by $50 \%$ and up to $90-94 \%$ inhibition was observed with $33-100 \mu \mathrm{M}$ concentrations (10).
Meanwhile there are 23 ongoing clinical trials in China and 6 trials in USA and Europe, that evaluate the use of CQ for COVID-19 therapy, pre-exposure prophylaxis and post-exposure prophylaxis, although the results are pending (12). Severe expert opinion based guidelines recommend to include CQ or HCQ in the treatment protocols of severe cases of COVID-19. The Dutch Center of Disease control (CDC), in a public document on its website, suggested to consider a HCQ regimen in adults in a dose of $600 \mathrm{mg}$ of HCQ at baseline followed by $300 \mathrm{mg}$ after 12 hours on day 1, then $300 \mathrm{mg}$ BID orally on days 2-5 days (Dutch, Accessed on 14th March 2020) (13). The Italian group of intensive care experts GiViTI recommends CQ $500 \mathrm{mg}$ BID or HCQ 200 mg BID for 5 days according to clinical severity (Teleconference in Italian, Accessed on 14th March 2020) (14). Belgian group experts recommend HCQ $400 \mathrm{mg}$ at suspicion or diagnosis, 400mg 12 hours later followed by 200mg BID up to Day 5 (15). Tehran group recommends for health care providers prophylaxis with $200 \mathrm{mg}$ hydroxychloroquine per day, except for those with any contraindication. For post exposure cases, a loading dose of $600-800 \mathrm{mg}$ on the first day followed by $200 \mathrm{mg}$ daily is recommended (16).

The dose of chloroquine administered should target plasma concentration in a range of $1-3 \mu \mathrm{M}$, that is both safe and effective according to in-vitro studies discussed above. According to Mackenzie a cumulative dose of $5 \mathrm{~g}$ of chloroquine over a period of approximately 3 weeks is necessary to reach a plasma concentration of $1 \mu \mathrm{M}$ and 10 grams to reach plasma concentration of 10 $\mu \mathrm{M}$ (17). In this report, the safe dosage zone was calculated to be less than $4.0 \mathrm{mg} / \mathrm{kg}$ per day for chloroquine and less than $6.5 \mathrm{mg}$ / $\mathrm{kg}$ per day for hydroxychloroquine, while the toxic threshold is 5.1 and $7.8 \mathrm{mg} / \mathrm{kg}$ per day, respectively.

\section{Lopinavir/ritonavir}

Many in vitro studies have shown that SARS-CoV could be inhibited by LPV/r in given in commonly prescribed dosing (18). In a clinical trial by Chu et al, 41 patients with SARS, followed for 3 weeks, were treated with a combination of lopinavir/ritonavir and ribavirin (19). Patients were administered lopinavir (400 mg)/ ritonavir $(100 \mathrm{mg})$ orally every 12 hours for 14 days. The clinical progress and virological outcomes were monitored and compared to 111 patients treated with ribavirin only, who served as historical control. The adverse clinical outcome (ARDS or death) was significantly lower in the treatment group than in the historical control $(2.4 \%$ vs $28.8 \%, p<0.001)$ on day 21 after the onset of symptoms. Patients had a decreasing viral load and rising peripheral lymphocyte count.

Another study by Park et al assessed the efficacy of ribavirin and LPV/r as post-exposure prophylaxis for healthcare workers (HCWs) exposed to patients with severe MERS-CoV pre-isolation pneumonia (20). Lopinavir/ritonavir was administered orally at a dose of $400 \mathrm{mg} / 100 \mathrm{mg}$ every $12 \mathrm{~h}$ for $11-13$ days. Ribavirin was administered orally at a loading dose of $2000 \mathrm{mg}$ followed by 1200 mg every $8 \mathrm{~h}$ for 4 days and then $600 \mathrm{mg}$ every $8 \mathrm{~h}$ for 68 days. Post-exposure prophylaxis was associated with $40 \%$ decrease in 
462-465

Tab. 1. Proposed prophylactic regimes of chloroquine, hydroxychloroquine and lopinavir/ritonavir for prevention of COVID.

\begin{tabular}{|c|c|c|}
\hline Drug & Prophylactic regime induction & Duration of prophylaxis \\
\hline Hydroxychloroquine (13-16) & $5 \mathrm{mg} / \mathrm{kg} /$ day for 5 days in two divided doses, then $2.5 \mathrm{mg} / \mathrm{kg} /$ day once daily & \multirow{3}{*}{14 days or until risk persists } \\
\hline Chloroquine (14) & $8 \mathrm{mg} / \mathrm{kg} /$ day for 5 days in two divided doses, then $4 \mathrm{mg} / \mathrm{kg} /$ day once daily & \\
\hline Lopinavir/ritonavir $(19,20)$ & $400 / 100 \mathrm{mg}$ twice a day & \\
\hline
\end{tabular}

Tab. 2. Proposed prophylactic measures for patients in high-risk groups for COVID-19 severe pneumonia.

\begin{tabular}{lll}
\hline High-risk group & Scenario & Proposed measures* \\
\hline $\begin{array}{l}\text { Seniors }>\text { 65 years } \\
\begin{array}{l}\text { Patients with commorbidities } \\
\text { Immunosuppressed patients }\end{array}\end{array}$ & $\begin{array}{l}\text { Community outbreak, no close contact } \\
\text { with a confirmed case }\end{array}$ & Prophylactic use of HCQ or CQ until outbreak control \\
\cline { 2 - 3 } & Close contact with a confirmed case & $\begin{array}{l}\text { Prophylactic use of HCQ or CQ days and/or LOP/r } \\
\text { until outbreak control }\end{array}$ \\
\cline { 2 - 3 } $\mathrm{CQ}=$ chloroquine, $\mathrm{HCQ}=$ hydroxychloroquine, $\mathrm{LPV} / \mathrm{r}=$ lopinavir/ritonavir & $\begin{array}{l}\text { Early treatment with CQ or HCQ and/or antivirals according } \\
\text { to local protocols }\end{array}$ \\
\hline
\end{tabular}

* prophylaxis should be given under strict medical supervision and respecting the contraindications and risk factors. HCQ is preferred to CQ due to more favourable safety profile.

the risk of infection among HCW. There were no severe adverse events during PEP therapy.

This data reveal that LPV/r has a potential to prevent and mitigate the course of a coronavirus infection, especially in the early stage (18). However, this data is from the trials with SARS or MERS coronaviruses and the results of recent LPV/r trials in COVID-19 are still pending.

\section{Proposed medical prophylactic measures in high risk groups}

The proposed prophylactic regimes of hydroxychloroquine, chloroquine and lopinavir/ritonavir is presented in Table 1. The dosing of HCQ and CQ was calculated to reach and maintain a plasma steady state concentration of $1-3 \mathrm{umol} / \mathrm{L}$ that is both safe and effective to decrease viral replication as discussed above. Given the narrow therapeutic window, body weight dosing is preferred to fixed dose regime. Contraindications for chloroquine has to be thoroughly considered especially the risk of hypoglycaemia in diabetic patients. LOP/r should be used instead in patients where HCQ or CQ use is risky.

The prophylactic measures for high-risk groups for severe COVID-19 are summarized in the Table 2. We suggest that patients with high risk of severe COVD-19 take a short prophylactic course of available drugs shown to inhibit the SARS-CoV proteases, i.e. hydroxychloroquine and/or lopinavir/ritonavir. If hydroxychloroquine is not available chloroquine should be used instead.

\section{Conclusions}

There is a striking difference in the case fatality rate among various risk groups. The high-risk groups comprise patients with advanced age, comorbidities and immunosuppressed patients.

Current strategies to control the outbreak of COVID-19 have been non-discriminatory and have implied draconian epidemiological measures such as lockdowns of entire countries for a long period of time. Their long-term effectiveness remains to be proven.
We propose another approach. More consideration should be given to high risk groups, as they carry the highest risk of complicated course of the disease as well as the highest burden for the limited health care resources of affected countries.

We suggest short-term prophylactic use of approved medications with established SARS-CoV-19 anti-viral activity in highrisk groups. We propose short course of hydroxychloroquine or chloroquine and/or lopinavir/ritonavir. These drugs are generally safe and well tolerated. The risk of use in high risk groups is acceptable. Especially when confronted with the $40 \%$ mortality of severe COVID-19.

Analysis of the impact of these measures reveals potential to reduce the case fatality rate in these large high-risk groups significantly. Reduction of CFR seems to be vital to mitigate the medical, psychological, social and economic impact of the COVID-19 pandemics.

Given the rapid spread of the pandemics, high mortality and resulting paralysis of societal functioning, we believe the proposed measures have a favourable risk/benefit ratio and should be considered in scientifically controlled setting.

\section{References}

1. Zhu N, Zhang D, Wang W, Li X, Yang B, Song J et al. A Novel Coronavirus from Patients with Pneumonia in China, 2019. New Engl J Med 2020; 382 (8): 727-733.

2. Zhou P, Yang XL, Wang XG, Hu B, Zhang L, Zhang W et al. A pneumonia outbreak associated with a new coronavirus of probable bat origin. Nature 2020; 579 (7798): 270-273.

3. Wu Z, McGoogan JM. Characteristics of and Important Lessons From the Coronavirus Disease 2019 (COVID-19) Outbreak in China: Summary of a Report of 72314 Cases From the Chinese Center for Disease Control and Prevention. Jama 2020.

4. Zhou F, Yu T, Du R, Fan G, Liu Y, Liu Z et al. Clinical course and risk factors for mortality of adult inpatients with COVID-19 in Wuhan, China: a retrospective cohort study. The Lancet 2020. 
5. Guan WJ, Ni ZY, Hu Y, Liang WH, Ou CQ, He JX et al. Clinical Characteristics of Coronavirus Disease 2019 in China. New Engl J Med 2020.

6. Hoffmann M, Kleine-Weber H, Schroeder S, Kruger N, Herrler T, Erichsen $S$ et al. SARS-CoV-2 Cell Entry Depends on ACE2 and TMPRSS2 and Is Blocked by a Clinically Proven Protease Inhibitor. Cell 2020.

7. Fang L, Karakiulakis G, Roth M. Are patients with hypertension and diabetes mellitus at increased risk for COVID-19 infection? The Lancet Resp Med 2020.

8. Krishna S, White NJ. Pharmacokinetics of quinine, chloroquine and amodiaquine. Clinical implications. Clin Pharmacokin 1996; 30 (4): 263-299.

9. Wang M, Cao R, Zhang L, Yang X, Liu J, Xu M et al. Remdesivir and chloroquine effectively inhibit the recently emerged novel coronavirus (2019-nCoV) in vitro. Cell Res 2020; 30 (3): 269-271.

10. Vincent MJ, Bergeron E, Benjannet S, Erickson BR, Rollin PE, Ksiazek TG et al. Chloroquine is a potent inhibitor of SARS coronavirus infection and spread. Virology J 2005; 2 (1): 69.

11. Ducharme J, Farinotti R. Clinical pharmacokinetics and metabolism of chloroquine. Clin Pharmacokin 1996; 31 (4): 257-274.

12. Cortegiani A, Ingoglia G, Ippolito M, Giarratano A, Einav S. A systematic review on the efficacy and safety of chloroquine for the treatment of COVID-19. J Crit Care 2020.

13. COVID-19 Bijlage 8 bij LCI-richtlijn. Medicamenteuze behandelopties bij opgenomen patiënten met COVID-19 2020, March 13 [Available from: https://ci.rivm.nl/covid-19/bijlage/medicamenteuze-behandelopties.
14. GiViTI CdC. 10 MARZO VIDEOCONFERENZA COVID-19 2020, March 10 [Available from: http://giviti.marionegri.it/10-marzovideoconferenza-covid-19/.

15. INTERIM CLINICAL GUIDANCE FOR PATIENTS SUSPECTED OF/CONFIRMED WITH COVID-19 IN BELGIUM Belgium 2020 March 16th [Available from: https://epidemio.wiv-isp.be/ID/Documents/ Covid19/COVID-19_InterimGuidelines_Treatment_ENG.pdf.

16. Pourdowlat G, Panahi P, Pooransari P, Ghorbani F. Prophylactic Recommendation for Healthcare Workers in COVID-19 Pandemic. Adv J Emerg Med 2020.

17. Mackenzie AH. Dose refinements in long-term therapy of rheumatoid arthritis with antimalarials. Amer J Med 1983; 75 (1, Part 1): 40-45.

18. Yao TT, Qian JD, Zhu WY, Wang Y, Wang GQ. A systematic review of lopinavir therapy for SARS coronavirus and MERS coronavirusA possible reference for coronavirus disease-19 treatment option. J Med Virol 2020.

19. Chu CM, Cheng VC, Hung IF, Wong MM, Chan KH, Chan KS et al. Role of lopinavir/ritonavir in the treatment of SARS: initial virological and clinical findings. Thorax 2004; 59 (3): 252-256.

20. Park SY, Lee JS, Son JS, Ko JH, Peck KR, Jung Y et al. Postexposure prophylaxis for Middle East respiratory syndrome in healthcare workers. J Hosp Infect 2019; 101 (1): 42-46.

21. Gautret P, Lagier JC, Parola P, Hoang VT, Meddeb L, Mailhe M et al. Hydroxychloroquine and azithromycin as a treatment of COVID-19: results of an open-label non-randomized clinical trial. Int J Antimicrob Agents 2020: 105949 . 